\title{
Fornix transections disrupt the ontogeny of latent inhibition in the rat
}

\author{
MICHELLE M. NICOLLE \\ University of North Carolina, Chapel Hill, North Carolina \\ CRAIG C. BARRY \\ NSI Technology Services, Research Triangle Park, North Carolina \\ BELLINA VERONESI \\ U.S. Environmental Protection Agency, Research Triangle Park, North Carolina \\ and \\ MARK E. STANTON \\ U.S. Environmental Protection Agency, Research Triangle Park, North Carolina \\ and University of North Carolina, Chapel Hill, North Carolina
}

\begin{abstract}
In three experiments, we examined the ontogeny of latent inhibition in a conditioned tasteaversion paradigm. In the first experiment, 18-, 25-, and 32-day-old rats received a pairing of a $0.6 \%$ Sanka solution with an i.p. injection of $\mathrm{LiCl}(0.75 \%$ b.w., $0.4 \mathrm{M})$ or physiological saline either after four preexposures to the taste or control treatment without taste preexposure. Impairment of conditioning by taste preexposure (latent inhibition) was evident at 32 days of age, but not at 18 or 25 days of age. In Experiment 2, we investigated the possibility that our failure to observe latent inhibition in 18-day-olds resulted from the particular experimental parameters employed in Experiment 1. In Experiment 2, taste-exposure durations were longer, the retention interval between conditioning and testing was shorter, and deprivation conditions were more typical of those used with preweanling subjects. Again, no evidence of latent inhibition was found. In Experiment 3, we examined the effect of sham or fornix lesions at 18 days of age on latent inhibition at 32 days of age. Lesioned subjects exhibited equivalent conditioned taste aversions but failed to show latent inhibition. Thus, latent inhibition of taste-aversion learning develops between 18 and 32 days of age in the rat, and this development is disrupted by fornix transection during infancy. These findings suggest a role for septohippocampal maturation in the ontogeny of latent inhibition.
\end{abstract}

In recent years, there has been impressive progress in the study of the ontogeny of learning in animals (Kail \& Spear, 1984; Spear \& Campbell, 1979). One principle that has arisen from this work is that the emergence in development of associative learning depends on matura-

Portions of this article are based on a thesis submitted by Michelle M. Nicolle to the Department of Psychology, University of North Carolina at Chapel Hill, in partial fulfillment of the requirements for graduation with honors. Special thanks are extended to David Eckerman for his role as reader of the thesis, and Michela Gallagher for also serving as reader and for contributing to this manuscript with helpful advice, criticism, and suggestions. Thanks are also due to Chris Murchison and Chrisley V. Pickens for expert technical assistance, and to Phil Bushnell and David Peele for reviewing an earlier version of this manuscript. Disclaimer: This manuscript has been reviewed by the Health Effects Research Laboratory, U.S. Environmental Protection Agency, and approved for publication. Mention of trade names or commercial products does not constitute endorsement or recommendation for use. Michelle Nicolle is now at the Curriculum in Neurobiology, University of North Carolina, Chapel Hill, NC 27514. Address correspondence to Mark E. Stanton, Neurotoxicology Division (MD-74B), U.S. Environmental PTotection Agency, Research Triangle Park, NC 27711. tion of both the sensory systems and the response systems that are engaged during the learning episode. For example, classically conditioned responses (CRs) that depend on processing of gustatory or olfactory information emerge earlier than CRs that depend on processing of visual or auditory information (Gemberling \& Domjan, 1982; Rudy \& Cheatle, 1979; Rudy, Vogt, \& Hyson, 1984). In many cases, development of primary sensory function in a given modality precedes by a few days associative learning capacity in that same modality (Hyson \& Rudy, 1984; Moye \& Rudy, 1985). Similarly, learned associations between two events can be shown earlier in ontogeny with some effector systems (somatomotor) than with others (autonomic), and the ability to respond unconditionally in a given effector system developmentally precedes conditioning of that system. This has been clearly shown with both heart-rate conditioning (Campbell \& Ampuero, 1985; Sananes, Gaddy, \& Campbell, 1988) and endocrine conditioning (Jacobs, Stanton, \& Levine, 1986).

Another general principle that is emerging is that maturation of simple associative learning processes precedes 
that of higher order or more complex learning processes (Rudy et al., 1984). For example, conditioning of temporally contiguous events appears earlier in development than conditioning of temporally separated events (Castro, Paylor, \& Rudy, 1987; Gregg, Kittrell, Domjan, \& Amsel, 1978; Moye \& Rudy, 1987; Rudy \& Cheatle, 1979; Stanton, 1982), reference memory develops earlier than working memory (Green \& Stanton, 1989), cue learning develops earlier than spatial learning in a spatial navigation task (Rudy, Stadler-Morris, \& Albert, 1987), and, in instrumental learning, a variety of expectancy-mediated extinction and contrast effects emerge later in development than simple acquisition and extinction (Amsel \& Stanton, 1980). These examples of the delayed emergence of more complex forms of learning are often viewed as reflecting the engagement of later developing "integrative" neural systems that are not tied to any particular sensory modality. For example, a number of investigators have noted that performance on tasks that are sensitive to hippocampal damage in the adult generally exhibits a relatively late emergence in ontogeny (Altman, Brunner, \& Bayer, 1973; Amsel \& Stanton, 1980; Castro et al., 1987; Douglas, 1975; Nadel \& Zola-Morgan, 1984; Rudy et al., 1987).

Although there now exist a large number of behavioral studies showing a correlation between hippocampal development and the ontogeny of "higher order" learning and memory phenomena, very few published studies have experimentally tested this apparent relationship by examining the effects of infant limbic system damage on the early ontogeny of these phenomena (Lobaugh, Bootin, \& Amsel, 1985; Saperstein, Kucharski, Stanton, \& Hall, 1989). In the present study, we sought to further address this issue in relation to a phenomenon in Pavlovian conditioning known as latent inhibition (Lubow, 1973).

Latent inhibition refers to the well-documented phenomenon that preexposure to a conditioned stimulus (CS) retards subsequent learning when the CS is later paired with a normally effective unconditioned stimulus (US). Many studies have shown that hippocampal damage impairs latent inhibition: animals with hippocampal damage that have had prior exposure to a CS typically learn as readily as their counterparts that have had no prior CS exposure (Ackil, Mellgren, Halgren, \& Frommer, 1969; Best \& Orr, 1973; Gallagher, Meagher, \& Bostock, 1987; Solomon \& Moore, 1975).

Previous developmental studies of latent inhibition of taste-aversion conditioning have yielded conflicting results and little detailed information regarding the age at which this phenomenon first emerges (Franchina, Domato, Patsiokas, \& Griesemer, 1980; Klein, Mikulka, Domato, \& Hallstead, 1977; Misanin, Guanowsky, \& Riccio, 1983). And, although some writers have attributed the development of latent inhibition to hippocampal maturation (Nadel \& Zola-Morgan, 1984), there have been, to our knowledge, no studies of the effects of early hippocampal damage on the subsequent ontogeny of this phenomenon. The purpose of the present study was to provide more information on both of these issues. First, we sought to examine the ontogeny of latent inhibition of taste aversion over a narrower age range -18 to 32 days - than has been done previously (Experiments 1 and 2). Second, in the present study, we asked whether early damage to the fimbria-fornix would impair latent inhibition at the age of its first appearance (Experiment 3).

\section{EXPERIMENT 1}

Previous developmental studies of latent inhibition in taste-aversion learning have tended to focus on the weanling period or to compare weanling rats and adults (Franchina et al., 1980; Klein et al., 1977; Misanin et al., 1983). In the first experiment, we sought to test several age groups over a narrower age range under the same experimental conditions. We examined latent inhibition of taste-aversion learning in 18-, 25-, and 32-day-old rats. This age range covers both the late preweanling and the early weanling periods of development. Our aim was to identify the age at which latent inhibition first occurs.

\section{Method}

Subjects. Twenty-seven 18-day-old, 30 25-day-old, and 23 32day-old Long-Evans rats were the subjects. These subjects were drawn from 11 litters $(4,4$, and 3 litters, respectively, at 18,25 , and 32 days of age). Littermates were assigned to each of the four experimental groups in this study with the restriction that no more than 1 female and 1 male from each litter was assigned to a given group. Data from 125 -day-old animal were discarded as an outlier (i.e., because it was more than 5 standard deviations away from the mean of the remaining subjects in its group). The rats were offspring of time-bred females obtained from Charles River (Raleigh, NC) on Day 2 of gestation. Offspring were raised in the animal colony at the Neurotoxicology Division, U.S. Environmental Protection Agency, Research Triangle Park, NC. All subjects were maintained on a 12-h light, 12-h dark photoperiod, with light onset at 7:30 a.m. The pups were born and housed with their mothers on a bed of wood shavings in plastic cages measuring $48 \times 27 \times$ $20 \mathrm{~cm}$. All litters were culled to 4 males and 4 females on the day after birth. Age of the pups was determined by checking for birth during the light phase of the light-dark cycle and designating that day as Postnatal Day 0. For the 18-day-old group, the rats were housed with their dams until the evening of Day 16 , at which time they were placed in individual cages and deprived of water $12 \mathrm{~h}$ before the start of the experiment. The PND 25- and 32-day-old groups were weaned on Day 21 and placed in group cages of 4 samesex siblings with ad-lib food and water available. Water deprivation of the 25- and 32-day-old groups began $12 \mathrm{~h}$ before the start of the experiment (Days 23 and 30, respectively). Thus, all three age groups were housed in individual cages with ad lib food available and water deprived $12 \mathrm{~h}$ before the experiment began, and were treated identically during preexposure, conditioning, and testing. They differed in that, during the interval between conditioning and water deprivation ( $24 \mathrm{~h}$ before testing), the 25 - and 32-day-olds were placed on ad-lib food and water, whereas the 18-day-olds were also reunited with their mothers.

Apparatus and Procedure. The procedure in this experiment was adapted from Kucharski and Spear (1985) and Rudy, Rosenberg, and Sandell (1977). A 2 (preexposure vs. nonpreexposure) $\times 2$ (lithium conditioning injection vs. saline control injection) factorial design was employed at three ages: 18, 25, and 32 days. Twelve hours after the subjects were placed in individual cages 
without water, they received a 1-min infusion of water to familiarize them with the procedure for presenting the liquid. During all infusion periods, the subjects were hand-held and the infusion tube (PE-50 polyethylene tubing) was placed on the subject's tongue. The subjects were given 1-min exposures to the solution, which was passed over their tongues at a rate of $0.58 \mathrm{ml}$ per minute. The rate of the infusion was regulated by a Harvard Infusion Pump fitted with a $20-\mathrm{ml}$ syringe containing, for the initial infusion, tap water, and later, a $0.6 \% \mathrm{w} / \mathrm{v}$ coffee solution (Sanka, decaffeinated, General Foods) in tap water. Two hours after the preliminary exposure to water, the subjects in the preexposed group were exposed to an identical infusion of the coffee solution. The subjects in the nonpreexposed group were handled for $1 \mathrm{~min}$ in place of the infusion. This procedure was repeated twice more in the day, separated by $2 \mathrm{~h}$. One hour after the third preexposure, water bottles were placed on the animal cages and the subjects were allowed access for $1 \mathrm{~h}$. Sixteen hours later, the subjects received their fourth preexposure (or handling).

Ten hours after the last preexposure, the conditioning session took place. This interval was chosen to minimize the possible contribution of proximal CS preexposure to our study (Best \& Gemberling, 1977). During conditioning, all subjects received a coffee exposure. For the preexposed group, this was the fifth time they had tasted coffee. For the nonpreexposed group, the flavor was novel. Within $2 \mathrm{~min}$ after the coffee exposure, the animals received the US, a $0.75 \%$ body weight (b.w.), i.p. injection of $0.4 \mathrm{M}$ lithium chloride (Group C-Li) or of physiologically balanced sodium chloride (Group C-Na). One hour after the last rat was injected, all subjects were returned to ad lib water and the 18-day-old animals were returned to their dams.

All subjects were water-deprived 3 days after conditioning. The rats in the 18-day-old group (now 21 days old) were weaned into individual cages with ad-lib food. Twenty-four hours later, the subjects were given a one-bottle test of the coffee solution. The solution was left on the cages for $30 \mathrm{~min}$. The bottles were weighed before and after testing to determine intake volume.

\section{Results}

The results of Experiment 1 appear in Figure 1. Latent inhibition emerged with development. There was no evidence of the phenomenon at 18 or 25 days, but it was clearly present at 32 days of age. Data were analyzed separately at each age by means of a 2 (preexposure vs. nonpreexposure) $\times 2$ (C-Li vs. $\mathrm{C}-\mathrm{Na}$ ) analysis of variance (ANOVA).

18 days. The 18-day-olds showed no evidence of latent inhibition (Figure 1, bottom panel). At this age, preexposure to a flavored solution did not inhibit acquisition of a conditioned taste aversion. Group $\mathrm{C}-\mathrm{Li}$ reduced consumption of the coffee solution relative to Group C$\mathrm{Na}$ to the same degree regardless of preexposure condition. This was confirmed by a two-way ANOVA on intake, which revealed a main effect of groups $[F(1,23)=$ $26.37, p<.001]$. There was no significant interaction of group $\times$ preexposure $(F=0.42)$.

25 days. The 25-day-olds also failed to show latent inhibition (Figure 1, middle panel). Like the 18-day-olds, there was comparable conditioned taste aversion (compare Groups $\mathrm{C}-\mathrm{Li}$ and $\mathrm{C}-\mathrm{Na}$ ) regardless of taste preexposure. This was confirmed by an ANOVA, which revealed a main effect of groups $[F(1,25)=11.55, p<$ $.003]$. There was no groups $\times$ preexposure interaction $(F=0.02)$.
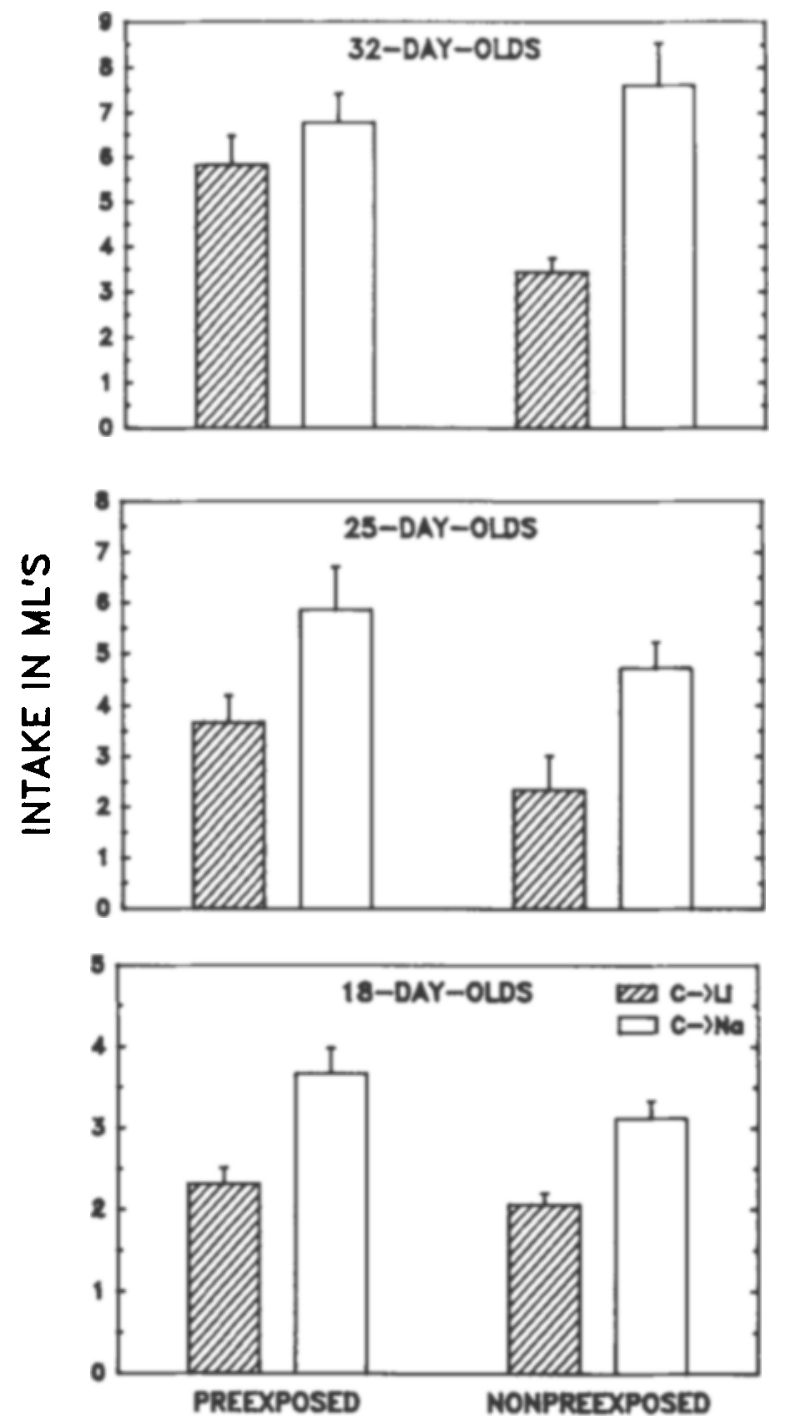

Figure 1. Mean ( $\pm S E M$ ) test intakes of the coffee solution (in ml) by the four treatment groups in Experiment 1, run at each of three postnatal ages of conditioning (18, 25, and 32 days). During conditioning, the subjects received a pairing of the coffee (Sanka) solution with an injection of either $\mathrm{LiCl}$ (C-Li, hatched bars) or $\mathrm{NaCl}$ (C-Na, white bars). Conditioning was preceded by either four preexposures (preexposed) or no preexposures (nonpreexposed) to the solution. (Note change in scale of $y$ axis for 18-day-olds.)

32 days. In contrast to the younger age groups, the 32day-old animals showed latent inhibition (Figure 1, top panel). A two-way ANOVA revealed a main effect of groups $[F(1,19)=15.76, p<.001]$ and an interaction of groups $\times$ preexposure $[F(1,19)=6.08, p<.025]$. A Newman-Keuls analysis of mean intake scores on the 32-day-olds revealed that, in the nonpreexposed condition, Group C-Li drank significantly $(p<.01)$ less than Group $\mathrm{C}-\mathrm{Na}$, whereas, in the preexposed condition, Groups $\mathrm{C}-\mathrm{Li}$ and $\mathrm{C}-\mathrm{Na}$ did not differ reliably. NewmanKeuls tests also revealed that Group C-Li in the preexposed condition drank significantly more of the flavored 
solution than its counterpart in the nonpreexposed condition $(p<.05)$. At this age, flavor preexposure inhibited the development of a conditioned flavor aversion.

Taken as a whole, the results of the present experiment indicate that latent inhibition of taste-aversion learning emerges late in the weanling period in the rat.

\section{EXPERIMENT 2}

Experiment 1 showed that latent inhibition is present in 32-day-olds but not in 18- and 25-day-olds. In that experiment, training and testing procedures were held constant across age once the animals were deprived from their home environment. However, deprivation may have had a differential impact on the different age groups. More specifically, the deprivation procedure may have been more stressful for 18-day-olds, due to maternal separation, than for the older age groups. It is possible that the absence of latent inhibition in the 18-day-olds reflects differential stress from deprivation rather than age per se. Although this does not explain the absence of latent inhibition in 25-day-olds in Experiment 1, we were surprised that latent inhibition emerged so late in ontogeny and thought it would be worth testing the generality of our failure to find latent inhibition during the preweanling period. In Experiment 2, we again looked for latent inhibition, but under different experimental conditions. The conditions used in Experiment 2 were ones more conventionally used with preweanling rat pups (e.g., by Gregg et al., 1978). These included separation of the pups from their mothers for shorter periods of time, measurement of intake of solutions delivered through intraoral cannulas, and longer durations of flavor exposure. It has been shown that these deprivation conditions are not overly stressful in 18-day-old rat pups, insofar as the basal levels of the stress hormone corticosterone are unchanged (Stanton, Wallstrom, \& Levine, 1987).

In Experiment 2, we examined the effects of flavor preexposure on taste-aversion conditioning in rat pups aged 17-18 days. We employed a discrimination procedure (Stanton \& Nicolle, 1989) in which the animals were exposed to one flavor $(\mathrm{CS}+)$ paired with $\mathrm{LiCl}$ and another presented alone (CS-). A two-group design was employed to assess the effect of flavor preexposure. One group (PRE) received four preexposures to the CS+ flavor and the other group (CTL) received four preexposures to the $\mathrm{CS}$ - flavor prior to discrimination training.

\section{Method}

Subjects. Twelve 17-day-old Long-Evans rat pups drawn from three litters (4 pups per litter) were the subjects. One male and 1 female from each litter was assigned to the two principal groups of this experiment (see below) and, within these, to different subgroups created by various counterbalancing factors (see below). All other details were as stated in Experiment 1.

Deprivation and Cannulation. At 8:00 a.m. of Day 16 (the day of preexposure), the subjects were removed from their nests and housed in individual compartments $(8 \times 9 \times 13 \mathrm{~cm})$ of a Plexiglas incubator $(37 \times 29 \times 13 \mathrm{~cm})$. The incubator contained wood shavings and was maintained at $30^{\circ}-33^{\circ} \mathrm{C}$ by a General Electric heating pad placed underneath.

At the time of deprivation, the pups were weighed and fitted with oral cannulas according to the procedure described by Hall and Rosenblatt (1977). A 9-cm segment of curved guitar wire (No. 10, E string, $0.1 \mathrm{~mm}$ diam) was inserted into the ventral surface of the jaw, through the tongue, and out of the mouth. The nonflanged end of the cannula (Clay-Adams PE-10, $0.28 \mathrm{~mm}$ i.d. polyethylene tubing) was fitted over the end of the wire, which extended out of the mouth, and the wire was pulled back through the tongue and jaw. The flanged end of the cannula rested securely on the surface of the tongue. The other end of the cannula, which exited at the ventral surface of the jaw, was passed through the scruff of the neck. A small segment $(3-4 \mathrm{~cm})$ of polyethylene tubing (Clay-Adams, PE-50, $0.58 \mathrm{~mm}$ i.d.) was then friction-fitted over the end of the PE-10 segment of the cannula. The tubing segments were then heatfused together to prevent leakage. The absence of leakage was verified by infusing appproximately $0.1 \mathrm{ml}$ of tap water through the cannula. The completed cannula was held in position by a $2-3 \mathrm{~cm}$ piece of Scotch tape folded over it at the base of the scruff of the neck. Following this procedure, which took 1-2 min, each pup was returned to the Plexiglas incubator where it remained until the next phase of the experiment.

Procedure. The 12 pups were assigned to the following groups: preexposed (PRE) and control (CTL). Pups in Group PRE received four preexposures to the CS+ flavor on Day 16. Pups in Group CTL received four preexposures to the CS - flavor on Day 16. Subjects within each of these groups were counterbalanced for the CS + flavor (Sanka or saccharin) and the order in which the flavors were presented on the test day following conditioning (CS + first or CS - first).

The preexposure phase (on Day 16) consisted of four preexposures, each separated by $2 \mathrm{~h}$, beginning at 1:00 p.m. Each preexposure consisted of the following: The pup's bladder was voided by light stroking of the anogenital area with a soft artist's brush. This reduced inaccuracies in fluid-intake measurement as a result of urination during the infusion procedure. The cannula was rinsed with $0.1 \mathrm{ml}$ of tap water to ensure it was clear and intact. The mouth and genital area were dried with a paper tissue, and the preinfusion weight of the animal was determined to the nearest $0.01 \mathrm{~g}$. The pup was then replaced in its individual deprivation compartment. The pups were infused with either a $0.625 \%$ (w/v) Sanka solution or a $0.5 \%(w / v)$ saccharin solution using a Harvard Infusion Pump (Model 906). Each infusion lasted $15 \mathrm{~min}$ at a rate of $0.1 \mathrm{ml} / \mathrm{min}$. After each infusion, the pups were weighed, their cannulas were flushed with tap water, their mouths were towel-dried, and they were placed in fresh incubation chambers. The pups were returned to their mothers by 8:00 p.m. ( $1 \mathrm{~h}$ after the last preexposure).

The conditioning phase of the experiment began the following morning (Day 17), at 8:00 a.m., with deprivation. The cannulas of all pups were inspected for patency and were repaired or replaced if neccessary. The pups were then returned to their incubation compartments. The pups were exposed to their CS - flavor at 3:00 p.m. using the identical infusion procedure as described above. The CS+ flavor was infused at 7:00 p.m., immediately followed by a $0.75 \%$ b.w. injection of $0.4 \mathrm{M} \mathrm{LiCl}$. The order of the conditioning injection was not counterbalanced because this factor was found to be unimportant in prior studies (see Stanton \& Nicolle, 1989). The pups remained in fresh deprivation chambers until testing the following morning.

The first conditioning test was at 10:00 a.m. the morning of Day 18. Again, test infusions were conducted in the same manner as conditioning infusions. The tests were 15 -min infusions of either the $\mathrm{CS}+$ or the $\mathrm{CS}-$ followed by a second test at $2: 00 \mathrm{p} . \mathrm{m}$. of the alternate flavor. Intake was measured by the difference between pre- and postinfusion weights in grams and conditioning was de- 
fined as the difference in intake between the CS + and the CS flavors.

\section{Results}

The results of Experiment 2 appear in Figure 2. Data were analyzed by a $2 \times 2$ between-within ANOVA involving the factors of preexposure (PRE vs. CTL) and stimulus (CS + vs. CS - ). There was no evidence of latent inhibition in this experiment. Differences in intake of the $\mathrm{CS}+$ and $\mathrm{CS}-$ flavors were the same regardless of whether prior exposure was to the CS + flavor or the CS - flavor. This was confirmed by an ANOVA, which revealed a main effect of stimulus $[F(1,10)=40.65$, $p<.0001]$. There were no main effects or interactions involving the preexposure factor $(F \mathbf{s}<1)$.

The magnitude of the conditioning effect in the present study agrees closely with that seen in animals that receive no stimulus preexposure whatsoever. Another study of simple taste-discrimination learning from this laboratory, which used conditions very similar to the present experiment, revealed mean intakes for $\mathrm{CS}+$ and $\mathrm{CS}-$ of 0.15 and $0.67 \mathrm{ml}$, respectively (Stanton \& Nicolle, 1989). This serves as further evidence that stimulus preexposure failed to affect conditioning in the present study.

This finding confirms and extends the results of Experiment 1 . There was again no evidence of latent inhibition, despite a number of changes in procedure. These changes included exposure durations that were longer than in Experiment 1 (15 vs. $1 \mathrm{~min}$ ), a retention interval between conditioning and testing that was much shorter (15 vs. $82 \mathrm{~h}$ ), and deprivation conditions that did not entail the stress of early separation. It is therefore unlikely that the failure to obtain latent inhibition at 18 days of age in Experiment 1 resulted from procedural factors of this kind.

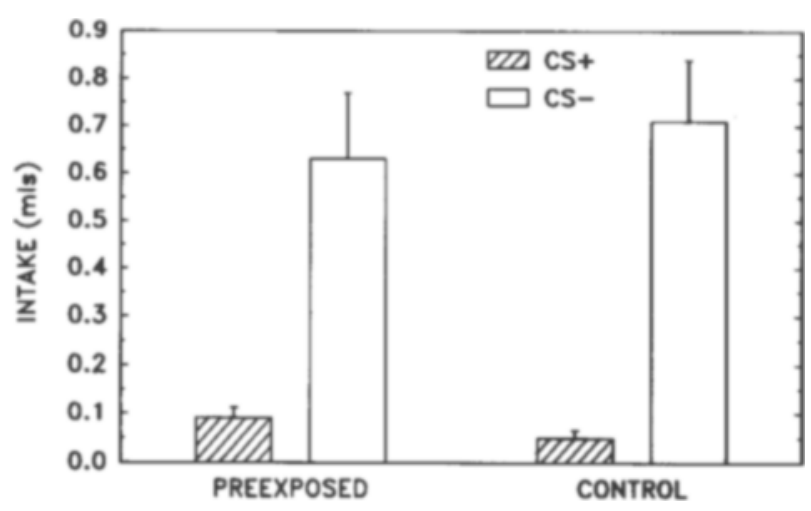

Figure 2. Mean ( $\pm S E M$ ) test intakes (in $\mathrm{ml}$ ) of the $\mathrm{CS}+$ and $\mathrm{CS}-$ flavors for the two conditioning groups in Experiment 2. During conditioning, the subjects were presented with the CS- flavor [saccharin or coffee (Sanka)] alone, and then, $4 \mathrm{~h}$ later, were presented with the alternate $\mathrm{CS}+$ flavor (coffee or saccharin) paired with an $\mathrm{LiCl}$ injection. Conditioning was preceded by four preexposures to either the CS + (preexposed) or the CS - (control) flavor. Preexposure, conditioning, and testing took place on Postnatal Days 16, 17, and 18 , respectively.

\section{EXPERIMENT 3}

The previous experiments indicated that latent inhibition is apparently absent during the preweanling period and slowly emerges during the postweanling period of development in the rat. This finding is in general agreement with previous studies showing that, around the weanling period, rats show deficits in latent inhibition relative to adults (Klein et al., 1977; Misanin et al., 1983). Moreover, it extends those studies by identifying more precisely the period in ontogeny when the phenomenon first appears.

The limbic system is involved in latent inhibition in adult animals (Ackil et al., 1969; Best \& Orr, 1973; Gallagher et al., 1987; Solomon \& Moore, 1975) and the ontogeny of latent inhibition parallels the protracted postnatal development of the hippocampus (Altman \& Bayer, 1975). Latent inhibition also joins a larger group of other limbicsystem-related learning and memory phenomena that emerge during postnatal development (e.g., see Amsel \& Stanton, 1980; Green \& Stanton, 1989; Rudy et al., 1987). It is therefore possible that hippocampal maturation contributes to the ontogeny of latent inhibition (Nadel \& Zola-Morgan, 1984). However, this apparent contribution of hippocampal maturation remains to be more directly tested. For example, it is currently not known whether early limbic system damage prevents the subsequent development of latent inhibition. The purpose of Experiment 3 was to address this issue.

\section{Method}

Subjects. Ninety-six Long-Evans rats from 12 litters (8 per litter) served as subjects. The subjects were obtained, housed, and cared for as described previously. One subject from each litter was assigned to one of eight experimental groups formed by a $2 \times 2$ $\times 2$ factorial design, thus yielding 12 animals per group (see below). However, groups eventually were composed of 10-12 animals because data from 2 animals were lost due to illness, data from 2 animals were discarded because of incomplete lesions (see below), and scores of 2 others were discarded because of experimental error. Thus, a total of 90 animals contributed data to the present experiment. These rats were 18 days old on the day of surgery and 32 days old on the day of conditioning.

Surgery. At 18 days of age, the subjects were deeply anesthetized by brief inhalation of $\mathrm{CO}_{3}$, placed prone on a flat surface, and their heads were aseptically cleaned. While being hand-held to ensure the skull surface was oriented horizontally, the subjects received a midline incision just over bregma. A scapel blade tip was used to puncture the skull bilaterally about $0.5 \mathrm{~mm}$ lateral of sagital sinus and $0.5 \mathrm{~mm}$ posterior of bregma. A fine wire (No. 10 guitar string) was then inserted vertically to a depth of $5 \mathrm{~mm}$ into each skull opening and rotated $60^{\circ}$ medially and $40^{\circ}$ laterally. Subjects assigned to the sham groups received identical midline incisions and skull punctures but no wire was inserted. Following the surgery, the incisions were bathed with a local anesthetic (Proparacaine, Maurry Biological Company) and closed with a drop of Vetbond $(3 \mathrm{M})$ and a single-suture. The pups were then allowed to recover in an incubator for $4 \mathrm{~h}$ before being reunited with their dams.

Histology. Following training and testing, 5 subjects per litter (4 fornix and 1 sham) were anesthetized with Nembutal $(35 \mathrm{mg} / \mathrm{kg}$ ) containing $1 \%$ heparin (50 units/ml) and perfused intracardially with a saline flush followed by a phosphate-buffered $4 \%$ solution of paraformaldehyde. The brains were allowed to fix in situ overnight 
at $4^{\circ} \mathrm{C}$ before being removed from the cranial cavity. Tissues were cryoprotected in $10 \%$ sucrose, frozen sectioned ( 40 microns) in the horizontal plane at the level of temporal hippocampus, and then incubated overnight in a modified Friedenwald-Koelle solution (Lynch, Lucas, \& Deadwyler, 1972) for acetylcholinesterase (AChE) staining. Additional sections were incubated in media containing either $0.01 \mathrm{mM}$ iso-OMPA to inhibit nonspecific cholinesterase or $0.01 \mathrm{mM}$ eserine to control for nonspecific staining.

Design. Of the 12 litters used in this experiment, half of each litter received sham surgery and half received fornix transections. The subjects in these surgical conditions were then assigned equally to either the preexposed or the nonpreexposed conditions, with half in each preexposure condition receiving a $0.75 \% \mathrm{~b} . \mathrm{w}$. injection of either physiological $\mathrm{NaCl}$ or $0.4 \mathrm{M} \mathrm{LiCl}$ on the conditioning trial. Thus, 1 subject in each litter was assigned to one of eight groups formed by a 2 (sham vs. fornix) $\times 2$ (preexposure vs. nonpreexposure) $\times 2(\mathrm{NaCl}$ vs. $\mathrm{LiCl}$ injection) factorial design. These assignments were counterbalanced for sex within and across litters.

Apparatus and Procedure. The apparatus and subsequent experimental procedures were the same as those used for the 32-dayolds in Experiment 1.

\section{Results}

Histological. The fimbria-fornix was completely transected and bilateral loss of hippocampal AChE staining
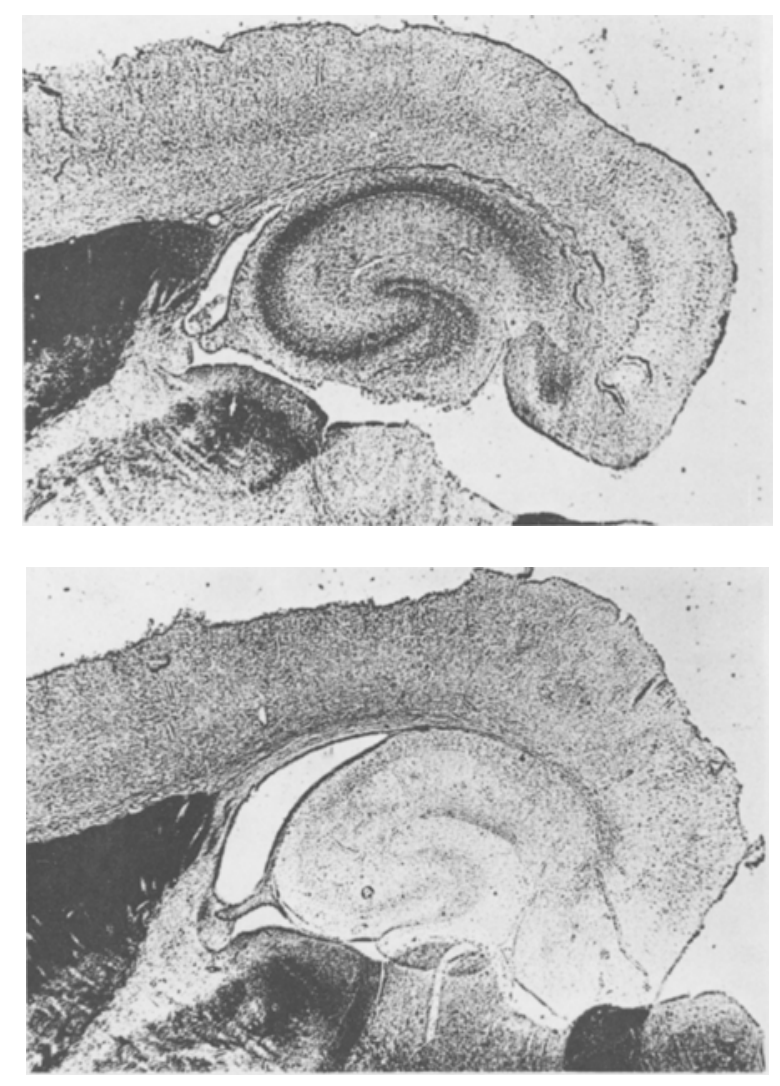

Figure 3. Horizontal sections showing acetylcholinesterase (AChE) in the hippocampus of representative sham-operated (above) and fornix-transected (below) rats. AChE staining was apparent in the caudate nucleus of both rats (left) but was absent in the hippocampus of the fornix rat.
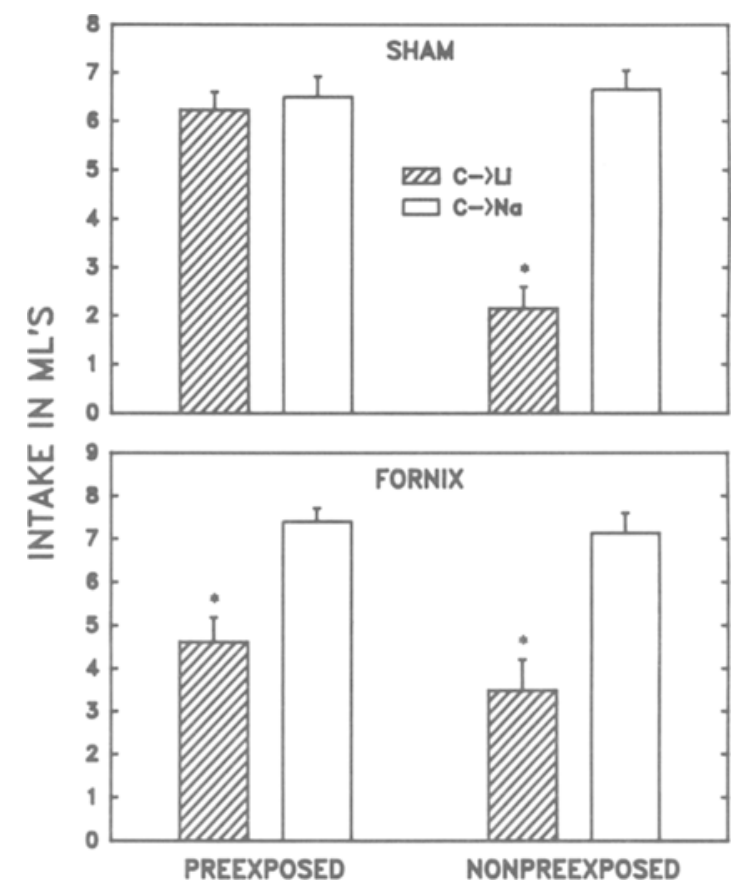

Figure 4. Mean $( \pm S E M)$ test intakes of the coffee solution (in $\mathrm{ml}$ ) by the four treatment groups in Experiment 3. During conditioning, the subjects received a pairing of the coffee (Sanka) solution with an injection of either $\mathrm{LiCl}$ (C-Li, hatched bars) or $\mathrm{NaCl}$ (C-Na, white bars). Conditioning was preceded by either four preexposures (preexposed) or no preexposures (nonpreexposed) to the solution. These groups were conditioned at 32 days of age after either sham (upper panel) or fornix (lower panel) lesions at 18 days of age. *C-Li differs from C-Na, $p<.01$.

was evident in all but 2 of the fornix animals examined. (Data from these 2 animals were excluded from the experiment.) Figure 3 illustrates the loss of AChE staining in the hippocampus of a typical fornix-sectioned animal relative to a sham control. Several animals also sustained damage to the anterior and dorsal regions of the thalamus. However, the presence, location, and extent of this damage was highly variable across these animals and did not correlate with the behavioral results, which were very consistent (see below). Thus, fornix damage appeared to be the aspect of the lesion that was common to all animals and that occurred with a consistency that would account for our behavioral observations.

Behavioral. The behavioral results of Experiment 3 appear in Figure 4. Latent inhibition was clearly evident in the sham-operated animals (upper panel) but not in the animals that received fornix transection in infancy (lower panel). The sham-operated animals showed a pattern of results that was similar to that of the 32-day-old animals in Experiment 1. Taste-aversion learning was clearly present in the nonpreexposed condition but not in the preexposed condition. That is, Group C-Li suppressed coffee intake relative to Group $\mathrm{C}-\mathrm{Na}$ in the nonpreexposed condition, whereas this suppression failed to occur in the preexposed condition. In contrast, the fornix-sectioned 
animals showed a pattern of results that resembled that shown by the younger age groups in Experiment 1. Fornix animals exhibited clear taste-aversion learning regardless of preexposure, as evidenced by the suppressed intake of Group C-Li relative to Group $\mathrm{C}-\mathrm{Na}$ in both the preexposed and the nonpreexposed conditions.

These observations were confirmed statistically by a 2 $\times 2 \times 2$ ANOVA and post hoc paired comparisons (Newman-Keuls). The ANOVA demonstrated a significant interaction of fornix $\times$ preexposure $\times$ groups $[F(1,82)=6.17, p<.02]$. Newman-Keuls tests indicated that, following sham surgery, Group $\mathrm{C}-\mathrm{Na}$ and Group C-Li differed reliably $(p<.01)$ in the nonpreexposed condition but not in the preexposed condition. In contrast, following fornix transection, these same groups differed reliably $(p<.01)$ regardless of preexposure condition. Mean coffee intake of Group C-Li in the preexposed-sham condition was elevated significantly over its counterparts in both the nonpreexposed-sham condition $(p<.01)$ and the preexposed-fornix condition $(p<.05)$. No other paired comparisons were significant.

These results agree with previous reports that limbic system damage disrupts latent inhibition (Ackil et al., 1969; Best \& Orr, 1973; Gallagher et al., 1987; Solomon \& Moore, 1975) and supports the view that maturation of the limbic system plays a role in the postnatal development of this phenomenon.

\section{GENERAL DISCUSSION}

In Experiment 1, simple taste-aversion learning was evident at all ages studied. These results confirm Kucharski and Spear's (1985) demonstration that this procedure is an effective way to study taste-aversion learning over the 18-32-day age range in the rat. Latent inhibition, on the other hand, appears to be age-dependent, developing relatively late in ontogeny. On Day 18 , there was no evidence of latent inhibition, but by Day 32 this learning phenomenon was firmly in place. Experiment 2 confirmed the absence of latent inhibition during the preweanling period with conditioning procedures that are more conventionally used with rats of this age. In Experiment 3, latent inhibition was prevented from appearing at 32 days of age by transecting the fornix on Day 18 , thus implicating maturation of the limbic system in the postnatal development of this phenomenon.

The results of the present study replicate and extend several previous studies indicating that latent inhibition is absent or impaired in animals aged 20-25 days. This has been reported for both active avoidance (Brennan \& Barone, 1976; Wilson, Phinney, \& Brennan, 1974) and taste-aversion learning (Klein et al., 1977; Misanin, Blatt, \& Hinderliter, 1985; Misanin et al., 1983; Wilson \& Riccio, 1973). However, it would be a mistake to emphasize a particular age range as critical, in an absolute sense, for the development of latent inhibition, because parametric and other methodological factors are likely to have a large effect on the point in ontogeny when this phenomenon can first be demonstrated. For example, more stimu- lus preexposure might cause latent inhibition to appear earlier in development, and indeed one study that employed eight preexposures to the CS (twice the number in the present one) showed significant latent inhibition of taste-aversion learning in rats at 20-25 days of age (Franchina et al., 1980). More recently, interference with conditioning by taste preexposure has been provisionally reported in 12-day-old rats by Kraemer, Hoffman, and Spear (1988). Assessment of the preexposure effect was problematic, however, because that study failed to indicate the effects of CS preexposure on the intake of unpaired control animals. That study also used a single taste preexposure $1 \mathrm{~h}$ before conditioning, and the impairment may therefore have reflected a short-term or "proximal" CS-preexposure effect (Best \& Gemberling, 1977) rather than latent inhibition. That proximal CS preexposure can interfere with conditioning during the neonatal period has been well documented in Rudy and Cheatle's (1979) studies of odor-aversion learning. In the present study, care was taken to ensure a sufficiently long interval between preexposure and conditioning to rule out a possible role of proximal CS preexposure. This was also done in a very recent and clear demonstration of latent inhibition of odor conditioning by Hoffman and Spear (1989). In that study, 10- and 18-day-old rats were trained to associate a 15-sec odor stimulus with footshock after 0,15 , or 45 discrete 1 -min preexposures to the odor. At 10 days, 15 exposures facilitated, whereas 45 exposures impaired, subsequent conditioning. In contrast, at 18 days, conditioning was impaired by both levels of preexposure. Thus, depending on the amount of preexposure and perhaps the stimulus modality involved in conditioning, latent inhibition can be demonstrated at earlier points in ontogeny. However, all studies, including the present one, suggest that the phenomenon increases with age. It is therefore perhaps best to view the ontogeny of latent inhibition in relative rather than absolute terms.

Measurement of many neurobiological parameters indicates that the hippocampal formation continues to develop during the pre- and postweanling periods in the rat (Altman \& Bayer, 1975; Pokorny \& Yamamoto, 1981a, $1981 b)$. It is therefore possible that the protracted postnatal maturation of this structure plays a direct role in the ontogeny of latent inhibition (Experiment 1). This possibility is strengthened by our finding (Experiment 3 ) that disrupting this maturation by fimbria-fornix transection in infancy prevents latent inhibition from appearing at the point in ontogeny when it was first seen in our study. This interpretation is in general agreement with a large body of evidence indicating that the development of the hippocampus parallels that of a wide range of learning and memory phenomena (Altman et al., 1973; Amsel \& Stanton, 1980; Bachevalier \& Mishkin, 1984; Douglas, 1975; Nadel \& Zola-Morgan, 1984). This interpretation is also consistent with a growing number of recent reports that limbic system damage in early infancy impairs or prevents the development of some of these phenomena (Bachevalier \& Mishkin, 1988; Dyck, Sutherland, \& Buday, 1985; Lobaugh et al., 1985; Pickens \& Stanton, 
1988; Saperstein et al., 1988). However, there are other interpretations of the present findings that cannot be ruled out. For example, the hippocampus could become functionally mature well before Postnatal Day 32 and the developmental emergence of latent inhibition at this age could reflect the later maturation of other, perhaps cortical, elements of the neural circuitry mediating this phenomenon. Direct tests of this alternative are difficult because this circuitry has not been characterized.

In this regard, it is worth discussing a related issuenamely, the problem of dating the onset of "hippocampal function." Early writers in this area made the simple assumption that the appearance in development of a behavior impaired by limbic damage in the adult indicates in a fairly direct way the developmental onset of hippocampal function. These writers also assumed that this onset occurs at an age, or within a narrow age range, that can be precisely identified-for example, 25-30 days of age in the rat (Altman et al., 1973, p. 582; Douglas, 1975 , p. 338). In the ensuing years, techniques for studying behavioral development have become more sophisticated, and information on the ontogeny of a wider range of hippocampally mediated learning phenomena has become available. This has encouraged the view that the onset of hippocampal function may occur much earlier in development (e.g., under 15 days of age in the rat) and that its expression in behavior depends on many factors, including stress, ecological demands, experimental parameters, and, perhaps most importantly, the particular behavioral phenomenon in question (Amsel \& Stanton, 1980; Nadel \& Zola-Morgan, 1984). This view is supported by more recent studies of the effects of early limbic system damage on learning in infant rodents. Such damage impairs development of the partial reinforcement extinction effect at 16 days (Lobaugh et al., 1985), working memory and olfactory reversal at 18 days (Pickens \& Stanton, 1988; Saperstein et al., 1989), and spatial navigation in a water maze at 22-23 days of age (Dyck et al., 1985). These studies suggest that the ontogeny of hippocampal function begins early and increments gradually. The findings of the present study should therefore not be taken as evidence that hippocampal function begins after 25 days of age in the rat. The late ontogeny of latent inhibition, and its disruption by fornix transection, shown in the present study may mean that the hippocampus must be more fully mature for latent inhibition to appear relative to other phenomena, or that other later maturing brain structures are critical for the effect.

\section{REFERENCES}

Ackil, J. E., Mellgren, R. L., Halgren, C., \& Frommer, G. P. (1969). Effects of CS preexposures on avoidance learning in rats with hippocampal lesions. Journal of Comparative and Physiological Psychology, 69, 739-747.

Altman, J., \& Bayer, S. (1975). Postnatal development of the hippocampal dentate gyrus under normal and experimental conditions. In R. L. Isaacson \& K. H. Pribram (Eds.), The hippocampus: Structure and development (Vol. 1, pp. 95-122). New York: Plenum.
Altman, J., Brunner, R. L., \& Bayer, S. A. (1973). The hippocampus and behavioral maturation. Behavioral Biology, 8, 557-596.

AmSEl, A., Stanton, M. (1980). Ontogeny and phylogeny of paradoxical reward effects. In J. S. Rosenblatt, R. A. Hinde, C. Beer, \& M. C. Busnel (Eds.), Advances in the study of behavior (Vol. 11, pp. 227-274). New York: Academic Press.

Bachevalier, J., \& Mishkin, M. (1984). An early and late developing system for learning and retention in infant monkeys. Behavioral Neuroscience, 98, 770-778.

BacheVAlier, J., \& Mishkin, M. (1988). Long-term effects of neonatal temporal cortical and limbic lesions on habit and memory formation in rhesus monkeys. Society for Neuroscience Abstracts, $14,1$.

Best, M. R., \& Gemberling, G. A. (1977). The role of short-term processes in the CS preexposure effect and the delay of reinforcement gradient in long-delay taste-aversion learning. Joumal of Experimental Psychology: Animal Behavior Processes, 3, 253-263.

BEST, P. J., \& ORR, J. (1973). Effects of hippocampal lesions on passive avoidance and taste aversion conditioning. Physiology of Behavior, 10, 193-196.

Brennan, J. F., \& Barone, R. J. (1976). Effects of differential cue availability in an active avoidance CS for young and adult rats. $D e$ velopmental Psychobiology, 9, 237-244.

Campbell, B. A., \& Ampuero, M. X. (1985). Dissociation of autonomic and behavioral components of conditioned fear during development in the rat. Behavioral Neuroscience, 99, 1089-1102.

Castro, C. A., Paylor, R., \& Rudy, J. W. (1987). A developmental analysis of the learning and short-term-memory processes mediating performance in conditional-spatial discrimination problems. Psychobiology, 15, 308-316.

Douglas, R. J. (1975). The development of hippocampal function. In R. L. Isaacson \& K. H. Pribram (Eds.), The hippocampus (Vol. 2., pp. 327-361). New York: Plenum.

Dyck, R. H., Sutherland, R. J., \& Buday, M. R. (1985). The ontogeny of mapping and non-mapping spatial strategies following neonatal hippocampal damage in rats. Society for Neuroscience Abstracts, $11,832$.

Franchina, J. J., Domato, G. C., Patsiokas, A. T., \& Gresemer, H. A. (1980). Effects of preexposures on sucrose taste aversion in weanling rats. Developmental Psychobiology, 13, 25-31.

Gallagher, M., Meagher, M. W., \& Bostock, E. (1987). Effects of opiate manipulations on latent inhibition in rabbits: Sensitivity of the medial septal region to intracranial treatments. Behavioral Neuroscience, 101, 315-324.

Gemberling, G. A., Domjan, M. (1982). Selective associations in one-day-old rats: Taste toxicosis and texture shock aversion learning. Joumal of Comparative \& Physiological Psychology, 96, 105-113.

GREEN, R. J., \& STANTON, M. E. (1989). Differential ontogeny of working memory and reference memory in the rat. Behavioral Neuroscience, 103, 98-105.

GregG, B., Kittrell, E. M. W., Domjan, M., \& Amsel, A. (1978). Ingestional aversion learning in preweanling rats. Journal of Comparative \& Physiological Psychology, 92, 785-795.

HaLl, W. G., \& Rosenblatt, J. S. (1977). Suckling behavior and intake control in the developing rat pup. Journal of Comparative \& Physiological Psychology, 91, 1232-1247.

HoffmanN, H, \& SPEAR, N. E. (1989). Facilitation and impairment of conditioning in the preweanling rat after prior exposure to the conditioned stimulus. Animal Learning \& Behavior, 17, 63-69.

Hyson, R. L., \& RUDY, J. W. (1984). Ontogeny of learning: II. Variation in the rat's reflexive \& learned responses to acoustic stimulation. Developmental Psychobiology, 17, 263-283.

JACOBS, E., StANTON, M. E., \& LeVINE, S. (1986, November). Differential ontogeny of behavioral and endocrine conditioned responses in the rat. Paper presented at the meeting of the International Society for Developmental Psychobiology, Annapolis, MD.

KAIL, R., \& SPEAR, N. E. (1984). Comparative perspectives on the development of memory. Hillsdale, $\mathrm{NJ}$ : Erlbaum.

Klein, S. B., Mikulka, P. J., Domato, G. C., \& Hallstead, C. (1977). Retention of internal experiences in juvenile and adult rats. Physiological Psychology, 5, 63-66. 
Kraemer, P. J., Hoffmann, H., \& Spear, N. E. (1988). Attenuation of the CS-preexposure effect after a retention interval in preweanling rats. Animal Learning \& Behavior, 16, 185-190.

KuCharsk, D., \& SPEAR, N. E. (1985). Potentiation and over-shadowing in preweanling and adult rats. Journal of Experimental Psychology: Animal Behavior Processes, 11, 15-34.

Lobaugh, N. M., Bootin, M., AMSel, A. (1985). Sparing of patterned alternation but not partial reinforcement effect after infant and adult hippocampal lesions in the rat. Behavioral Neuroscience, 99, 46-59.

LuBow, R. E. (1973). Latent inhibition. Psychobiology Bulletin, 79, 398-407.

Lynch, G. S., Lucas, P. A., \& Deadwyler, S. A. (1972). The demonstration of acetylcholinesterase containing neurons within the caudate nucleus of the rat. Brain Research, 45, 617-621.

Misanin, J. R., Blatt, L. A., \& Hinderliter, C. F. (1985). Age dependency in neophobia: Its influence on taste-aversion learning and the flavor-preexposure effect in rats. Animal Learning \& Behavior, 13, 69-76.

Misanin, J. R., Guanowsky, V., Riccio, D. C. (1983). The effect of CS-preexposure on conditioned taste aversion in young and adult rats. Physiology \& Behavior, 30, 859-862.

MOYE, T. B., \& RUDY, J. W. (1985). Ontogenesis of learning: VI. Learned and unlearned responses to visual stimulation in the infant hooded rat. Developmental Psychobiology, 18, 395-409.

MoYE, T. B., \& RUDY, J. W. (1987). Ontogenesis of trace conditioning in young rats: Dissociation of associative and memory processes. Developmental Psychobiology, 20, 405-414.

NADEL, L., \& Zola-MorGaN, S. (1984). Infantile amnesia: A neurobiological perspective. In M. Moscovitch (Ed.), Infant memory (pp. 145172). New York: Plenum.

Pickens, C. V., \& Stanton, M. E. (1988). Neonatal exposure to the limbic system neurotoxin, trimethyltin, impairs working memory in preweanling rats. Society for Neuroscience Abstracts, 14, 885.

PoKoRNY, J., \& YAMAMOTO, T. (1981a). Postnatal ontogenies of hippocampal CA1 area in rats: I. Development of dendritic arborization in pyramidal neurons. Brain Research Bulletin, 7, 113-120.

Pokorny, J., \& Y амamoto, T. (1981b). Postnatal ontogenies of hippocampal CA1 area in rats: II. Development of ultrastructure in stratum lacunosum and moleculare. Brain Research Bulletin, 7, 121-130.

Rudy, J. W., \& ChEATle, M. D. (1979). Ontogeny of associative learning: Acquisition of odor aversions by neonatal rats. In N. E. Spear \& B. A. Campbell (Eds.), Ontogeny of leaming and memory (pp. 157188). Hillsdale, NJ: Erlbaum.
Rudy, J. W., Rosenberg, L., \& Sandell, J. H. (1977). Disruption of a taste familiarity effect by novel exteroceptive stimulation. Journal of Experimental Psychology: Animal Behavior Processes, 3, 26-36.

Rudy, J. W., Stadler-Morris, S., Albert, P. (1987). Ontogeny of spatial navigation behaviors in the rat: Dissociation of "proximal" and "distal"-cue based behaviors. Behavioral Neuroscience, 101, 62-73.

Rudy, J. W., Vogt, M. B., Hyson, R. L. (1984). A developmental analysis of the rat's learned reactions to gustatory and auditory stimulation. In R. Kail \& N. E. Spear (Eds.), Comparative perspectives on the development of memory (pp. 181-208). Hillsdale, NJ: Erlbaum.

Sananes, C., Gaddy, J. R., Campbell, B. A. (1988). Ontogeny of conditioned heart rate to an olfactory stimulus. Developmental Psychobiology, 21, 117-133.

Saperstein, L. A., Kucharski, D., Stanton, M. E., \& Hall, W. G. (1989). Developmental change in reversal learning of an olfactory discrimination. Psychobiology, 17, 293-299.

Solomon, P. R., MOORE, J. W. (1975). Latent inhibition and stimulus generalization of the classically conditioned nictitating membrane response in rabbits (Oryclolagus caniculus) following dorsal hippocampal ablation. Journal of Comparative \& Physiological Psychology, 89, 1192-1203.

Spear, N. E., \& Campbell, B. A. (Eds.) (1979). Ontogeny of learning and memory. Hillsdale, $\mathrm{NJ}$ : Erlbaum.

Stanton, M. E. (1982). Performance of 11- and 14-day-old rats on a working memory problem. Behavioral \& Neural Biology, 36, 304-310.

Stanton, M. E., Nicolie, M. M. (1989). Taste discrimination leaming in preweanling rats. Manuscript submitted for publication.

Stanton, M. E., Wallstrom, J., \& Levine, S. (1987). Maternal contact inhibits pituitary-adrenal stress responses in preweanling rats. $D e$ velopmental Psychobiology, 20, 131-145.

Wilson, L. M., Phinney, R. L., \& Brennan, J. F. (1974). Age-related differences in avoidance behavior in rats following CS preexposure. Developmental Psychobiology, 7, 421-427.

WILSON, L. M., \& Riccio, D. C. (1973). CS familiarization and conditioned suppression in weanling and adult albino rats. Bulletin of the Psychonomic Society, 1, 184-186.

(Manuscript received December 15, 1988; revision accepted for publication September 15, 1989.) 